\title{
Research on the Choice of Knowledge Trading Pattern among Enterprises in Online Innovation Environment
}

\author{
Yi Li, Yuanjie Ni, Wei Liu and Wenxing Yan \\ School of Economics and Management, Chongqing University of Posts and \\ Telecommunications, Chongqing 400065, China \\ yili.cqupt@gmail.com,1813930016@qq.com,457719745@qq.com, \\ 394777882@qq.com
}

\begin{abstract}
In the network innovation environment, the knowledge trading between enterprises could be divided into traditional pattern (TP) and the E-commerce pattern (ECP). The two both have their advantages and disadvantages, so enterprises would face the problem. This paper generalizes the operation characteristics and the influence factors of two patterns. The mathematical model is used to analyze the selection mechanism of choosing two patterns, and the result illustrated that when the agency fee, the risk cost of ECP and the trading potential get bigger, the possibility that enterprises choose TP would get bigger, too; and when the explicitness of knowledge, cost of searching, trading incentive, the risk cost of TP and the reserve cost of ECP increase, the possibility that enterprises choose ECP would increase. When the reserve cost of ECP becomes big enough, it would make enterprises be more willing to choose hybrid pattern.
\end{abstract}

Keywords: knowledge trading, online innovation, E-commerce pattern, traditional pattern, mathematical model

\section{Introduction}

In the production and operation activities of enterprises, we often encounter problems that cannot be solved with inner knowledge. If we just depend on the inner power to research and develop the knowledge that we need, it may takes huge cost and long time, so enterprises always need to acquire knowledge from the outside [1-4]. The knowledge trading between enterprises is an important way for enterprises to acquire outside knowledge [5-6]. We could divide the knowledge trading into traditional pattern (TP) and the E-commerce pattern (ECP) according to the medium of exchange. The ECP could decrease the cost of searching and increase the range of knowledge trading [7], but enterprises should pay the agency fee. Although enterprises don't need to pay the TP's agency fee, it has a lack of the third-party monitoring, so it has a risk of free-rider [8]. Enterprises need to weigh the cost and the profit to solve the confusion about how to choose the fitter pattern, but the way doesn't have theoretical guidance so far. That makes it is necessary to research the knowledge trading between enterprises .

The existing researches of knowledge trading focus on the trading patterns and the influence factors. In the research of trading patterns, there are some scholars who create the knowledge trading model under the circumstances of the inner enterprises [8-9], and the enterprises in the supply chain [10], and scholars who create the knowledge trading model under the network innovation outsourcing circumstances based on the internet and Witkey [11-13]. In the research of influence factors, there are scholars who raise 
the type of knowledge [14] and the distance of knowledge [15-16] would influence the trade from the perspective of knowledge characteristics, and scholars who raise the risk of trading [10-17], the cost of searching [7], agency fee [10] and the willing of trading[18] would influence the knowledge trading from the perspective of trading environment.

The researches above talked about many aspects of knowledge trading, but they still had limitations: (1) the researches of trading model generally aimed at the single pattern to create the model, but ignored the comparison between two patterns; (2) the researches of influence factors just the qualitative analysis, there are rarely the researches of creating the mathematical model to carry on quantitative analysis.

Aiming at the limitations above, our paper borrows Liu De's idea of workers' selection behavior of knowledge sharing approach and creates mathematical model to analyze enterprises' selection mechanism of the two knowledge trading patterns [18]. Different from the previous researches, this model: (1) we consider two trading patterns' cost and profit at the same time, and dissect the balancing selection mechanism of knowledge trading patterns; (2) we bring the influence factors such as cost of searching, agency fee and the risk cost into consideration, that makes our paper closer to the reality and more detailed about the process of knowledge trading. Our research attempt to make the knowledge trading theory between enterprises be deepened and enhanced, and provide reference for the knowledge trading decision in the reality and knowledge trading supervision of third-party organization.

\section{Background}

In TP, when the enterprises need the outside knowledge, they would ask other surrounding enterprises for helping and acquiring knowledge through many forms such as visiting and learning. But with the development of network technology, enterprises could conduct knowledge trading with more enterprises on the network platform. The enterprises become the demand side of knowledge (demander) when they ask the outside world for help; and they would become the supply side of knowledge(supplier) when they provide knowledge. So the enterprises could be both demander and supplier [10].

\subsection{The Traditional Pattern}

The TP refer to the pattern that the enterprises who are familiar with each other set the trading agreement based on the reciprocal, and then carry on the knowledge transfer offline [5, 19]. The enterprises use different forms such as visiting and learning as the way of trading. Both side of trading have to come to an agreement that set both enterprises should keep the reciprocal relationship under some conditions.

The TP of knowledge trading always happens in the enterprises cluster such as supplychain, industry cluster and the standard alliance [10]. In the enterprises cluster, the knowledge that enterprises own are very similar, and the relationships between enterprises are not the competition but also the partnership, so the cluster's competitiveness would be improved if only the single enterprise's knowledge gets improved. The Toyota's supply-chain constructs the suppliers association and the learning team to strengthen the communication between enterprises in the alliance. In the end, they create the reciprocal cooperation atmosphere and establish the network of knowledge sharing, so that enterprises could carry on knowledge trading directly by the connection of the network. 


\subsection{E-commerce Pattern}

The ECP refer to the pattern that enterprises publish the need of knowledge on the Internet and outsource the innovation tasks to other enterprises, besides the deal would be completed online. The main bodies of ECP are the task promulgator (demander), the recipient (supplier) and the network service providers (the third-party) [20]. The both sides of trading should carry on trading as the regulations of the platform. The types of trading include the reward type, the bidding type and the sale type.

The reward type is that the task promulgators publish the innovation task one network platform, and the innovators complete the task and deliver achievement. Then the enterprises could choose the best achievement and reward the deliverers. The difference between the bidding type and the reward type is that the innovators don't need to make an achievement, instead they use the bid document to participate in the bidding. The sale type is that the innovators turn their knowledge, skills and wisdom to the knowledge products, then upload the products to the knowledge base and sell to enterprises actively. The famous network innovation platform MyEncore mainly uses the reward type, the NineSigma is bidding type, and InnoCentive are both reward type and bidding type. Nowadays, more and more enterprises have started searching for the knowledge that they need on these network platforms, and these platforms could provide Witkeys with a place to sell their ideas.

The two patterns have some similarities in some way, for example, there are trading risks in both two patterns. But the difference is that the trading risk of TP is caused by the lack of third-party's monitoring [18], while the risk of ECP is caused by the trading mechanism [21]. So both two patterns have their own advantages and disadvantages, enterprises would face the dilemma when they have to choose a better pattern. Enterprises should take their own characteristics and the outside environment into consideration, and weigh the cost and the profit of two patterns, so that they might make better decision. The paper attempts to construct a model to analyze the selection problem in order to get the selection mechanism.

\section{The Model}

According to the specific situation of TP and ECP, we take the searching cost, agency fee and the risk cost into consideration, and then we construct a mathematical model. With that, we analyze the interaction of two patterns to research enterprises' selection behavior of knowledge trading pattern.

\subsection{The Basic Hypothesis and the Description of Variables}

\subsubsection{The Both Sides' Basic Attribute}

Hypothesis 1: We regard the knowledge trading between enterprises as a long-term process, and the possibility that two enterprises could keep the trading relationship at every beginning of trading is $\sigma(0<\sigma<1)$. The higher $\sigma$ is, the higher possibility that two enterprises could carry on knowledge trading is [18].

Hypothesis 2: The possibility that the suppliers are willing to carry on trading with their knowledge is $p(0<p<1)$, and the possibility that the demander have a demand of knowledge that the supplier provide is $q(0<q<1)$, and both $p$ and $q$ reflect the enthusiasm that enterprises carry on knowledge trading. Setting the distance of knowledge is $x(0 \leq x \leq 1)$, that refer to the gap between the knowledge that suppliers provide and the knowledge that the demanders have already had. Assuming $q=1-x$, that means the bigger 
distance of knowledge is, the less possibility that they could carry on knowledge trading is. We can give an example that the enterprises who sell clothes have a bigger demand of the sales strategy of phone industry, while the demand of kneading skills is smaller.

\subsubsection{The Profit of Trading}

Hypothesis 3: Compared with ECP, the TP is completed through the actual contact offline, and it is helpful for the demander to absorb the new knowledge, that means the demander will acquire knowledge that have small distortion. So we could set the demander gets 1 as profit when they trade per unit of knowledge by TP. Because knowledge that traded by ECP is coded, so that we can't define the distortion. Then we set the demander' profit would be $\alpha(0 \leq \alpha \leq 1)$ when they trade the same per unit of knowledge by ECP. $\alpha$ refers to knowledge's degree of explicitness, when the degree becomes higher, that means the demander can absorb new knowledge more easily, then enterprises could get more profit.

Hypothesis 4: In the TP, the enterprises obey the reciprocal, so the supplier just lives on the return from receivers in the future without any other extra bonus; but in ECP, the supplier would receive a disposable sum $r$ paid when trading is done.

\section{Table 1. Definition of Variables}

\begin{tabular}{cl}
\hline Variables & \multicolumn{1}{c}{ Definition } \\
\hline The basic attribute & The possibility that enterprises could keep the trading relationship \\
$\delta$ & after every knowledge trading \\
$p$ & The possibility that enterprise become the supplier \\
$q$ & The possibility that enterprise become the demander \\
$x$ & The distance of knowledge \\
The traditional pattern & The sharing cost that the supplier pays for trading \\
$e$ & The searching cost that the demander pays for trading \\
$s$ & The supplier's risk cost \\
$\eta_{a}$ & The supplier's reserve cost \\
$c_{a}$ & The profit that the demander acquires \\
The E-commerce pattern \\
$\alpha$ & The reward that the supplier could get \\
$r$ & The coding cost that the supplier pays for trading \\
$f$ & The agency cost that the demander pays for trading \\
$\beta$ & The supplier's risk cost \\
$\eta_{b}$ & The supplier's reserve cost \\
$c_{b}$ &
\end{tabular}

\subsubsection{The Trading Cost}

Hypothesis 5: The supplier would have to pay $e(e \geq 0)$ as the trading cost (such as the manpower and material resources) when they trade per unit of knowledge by TP, while they would pay $f(f \geq 0)$ by ECP. $e$ and $f$ are both drawn independently from a uniform distribution $F(z)$ on $[0,1]$. According to the real situation, the demander would pay the 
searching cost when they try to find deals in TP, we set that $s$. In ECP, searching cost could be ignored, but enterprises still should pay for the agency fee, and we set that $\beta$.

Hypothesis 6: There is no one could supervise the trading process. As a result, something like the receivers wouldn't give their knowledge to the supplier for return happens easily [8]. Although ECP does have the third-party to supervise the process, something like stealing knowledge still happens [20]. So the suppliers in trading have to take the risk in both two patterns. We set the risk cost $\eta_{a} \geq 0$ in TP, and $\eta_{b} \geq 0$ in ECP.

Hypothesis 7: Whether the trading could be carried on mainly depends on the willingness of both sides. Only if the expected profit is bigger than cost, would the supplier provide knowledge. In TP, the reserve cost is $c_{a}\left(c_{a} \geq 0\right)$, that means the biggest cost that supplier could afford when they provide knowledge. And we assume that $c_{a}$ is set in order to keep the relationship more stable, and it couldn't be changed once it is set. Meanwhile we assume that the supplier's reserve cost is $c_{b}\left(c_{b} \geq 0\right)$ in ECP. The variables are all in Table 1.

\subsection{The Model's Operation Process}

At the beginning, the enterprises that have a short distance of knowledge set the reserve cost of TP $c_{a}$ based on the reciprocal, and they choose the TP to carry on knowledge trading. Then the network service providers would perfect the trading mechanism and set the agency fee $\beta$ to attract enterprises to choose ECP, meanwhile the supplier would set the reserve cost of ECP is $c_{b}$. At last, both sides in the trading would take the real situation, the expected profit and the cost into consideration and choose the better pattern. Picture 1 shows the model's operation time sequence.

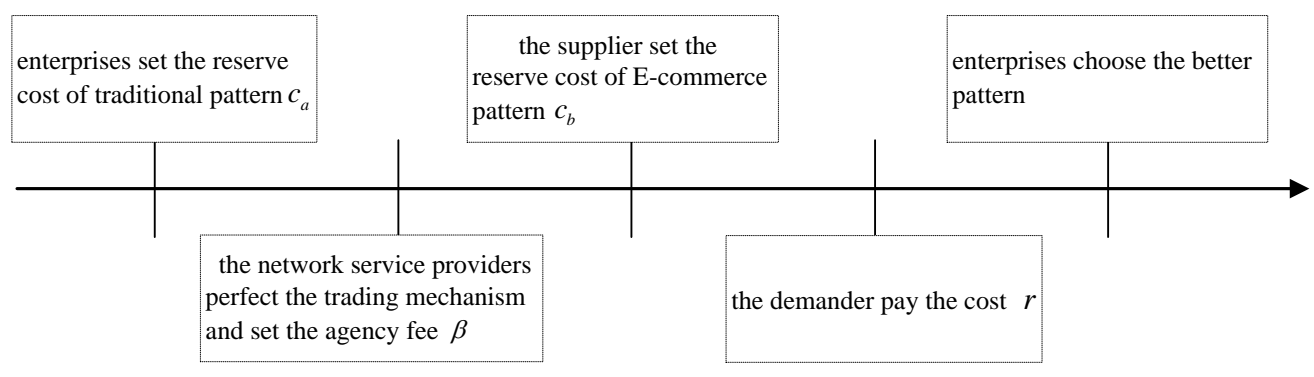

Figure 1. The odel's Operation Process

\section{Model Analysis}

This paper talks about the reserve cost of $\mathrm{TP} c_{a}$ first, then compares the profit and cost of two patterns and analyze the critical conditions of choosing TP, ECP or hybrid pattern. At last we consider the distance of knowledge $x$ and the reserve cost of ECP $c_{b}$ 's influence on choose trading mechanism.

\subsection{The Setting of the Reserve Cost of Traditional Pattern}

Assuming in the TP, every single enterprise could choose the reserve cost $c_{a}$ to make the lowest expected profit the highest in TP before the trading begin. The profit that enterprises 
acquire from knowledge trading includes the profit of this time and the profit of future's trading. The expected profit in any one future trading is

$$
\underbrace{p(1-x) F\left(c_{a}\right) \times 1-p(1-x) F\left(c_{a}\right) s}_{\text {the profit of demander }}+\underbrace{\left[-p(1-x) F\left(c_{a}\right) \eta_{a}-p(1-x) \int_{0}^{c_{a}} e d e\right]}_{\text {the profit of supplier }}
$$

The first part in (1) refers to the profit that enterprises acquire as the demander, and the second part refers to the profit that enterprises acquire as the supplier. When enterprises play the supplier roles in this time and pay the highest cost, the total profit that acquired by TP is the lowest, and the profit is

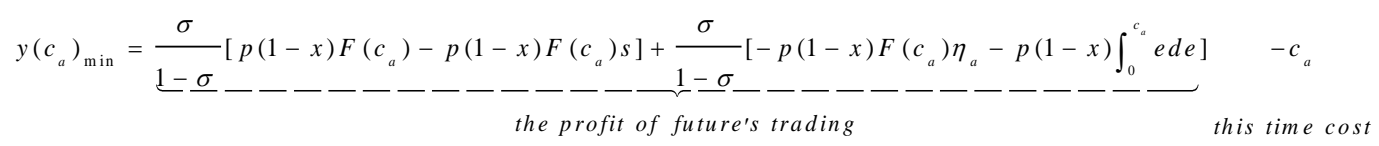

We set $A=\frac{\sigma}{1-\sigma} p$, and call it enterprises' trading potential of knowledge. It is determined by the relationship of knowledge trading between enterprises and the willingness that enterprises provide their knowledge [12].

We can get the highest $y\left(c_{a}\right)$ when we take derivatives and make the derived function 0 . Then the $c_{a}$ is the reserve cost, and that is

$$
c_{a}=\left(1-s-\eta_{a}\right)-\frac{1}{A(1-x)}
$$

From the formula (3), the reserve cost $c_{a}$ decreases with risk cost, searching cost and the distance of knowledge's increase, and increases with knowledge's trading potential's increase. That illustrated that enterprises tend to construct more stable reciprocal relationship with the enterprises that have near distance of knowledge, low trading risk, low searching cost and strong willingness of trading.

\subsection{The Critical Conditions for Enterprises to Choose Traditional Pattern}

The conditions that enterprises could choose TP are: the lowest profit in TP is greater than the highest profit in ECP. That means $y\left(c_{a}\right)_{\min }>y\left(c_{b}\right)_{\max }$. When the lowest coding cost $f$ is 0 (for example the enterprises give the existing scheme directly to others), enterprises could get the highest profit in ECP, and that is

$$
y\left(c_{b}\right)_{\max }=\frac{\sigma}{\underbrace{1-\sigma}_{\text {the profit of supplier }}---x(1-x) F\left(c_{b}\right) r-p(1-x) F\left(c_{b}\right) \eta_{b}]+\frac{\sigma}{1-\sigma}\left[p(1-x) F\left(c_{b}\right) \alpha-p(1-x) F\left(c_{b}\right) \beta\right]}
$$

The first part of (4) is the profit when enterprises play the supplier role, and the second part is the profit when enterprise is the demander. Because of $y\left(c_{a}\right)_{\min }>y\left(c_{b}\right)_{\max }$, we can get the conditions that $y\left(c_{a}\right)_{\min }=y\left(c_{b}\right)_{\max }$ is

$$
x_{1}=1-\frac{1}{A\left\{\left(1-s-\eta_{a}\right)-\sqrt{2 c_{b}\left[\alpha-\beta+r-\eta_{b}\right]}\right\}}
$$

That means when $x<x_{1}$, enterprises just choose TP to carry on knowledge trading. For example, when $x_{1}=0.6$, enterprises would carry on knowledge trading with other enterprises 
that the range of distance of knowledge is 0.6 , and $x_{1}=0$ means enterprises wouldn't just choose TP to carry on knowledge trading. So the condition that the situation that enterprises just only choose TP exists is $x_{1}>0$. Set

$$
c_{b 1}=\frac{\left(1-s-\eta_{a}-\frac{1}{A}\right)^{2}}{2\left[\alpha-\beta+r-\eta_{b}\right]}
$$

That means only if $c_{b}<c_{b 1}$, exists the situation that enterprises only choose TP. Finally we can get the condition that enterprises only choose TP: $x<x_{1}$ and $c_{b}<c_{b 1}$. So before choosing TP, enterprises should set the appropriate reserve cost of ECP according to distance of knowledge between enterprises.

\subsection{The Critical Condition that Enterprises Choose E-commerce Pattern}

Comparing the highest profit of TP to the lowest profit of ECP, we can get the critical condition that enterprises should only choose ECP is $y\left(c_{b}\right)_{\min }>y\left(c_{a}\right)_{\max }$. Enterprises could acquire the highest profit in TP when enterprises are the supplier and the sharing cost is 0. That means

$$
y\left(c_{a}\right)_{\max }=\frac{\sigma}{1-\sigma}\left[p(1-x) F\left(c_{a}\right)-p(1-x) F\left(c_{a}\right) s-p(1-x) F\left(c_{a}\right) \eta_{a}\right]
$$

Enterprises could acquire the lowest profit in ECP when enterprise is the supplier and pays the highest coding cost which is the reserve cost $c_{b}$.

$$
\begin{aligned}
y\left(c_{b}\right)_{\min }= & \frac{\sigma}{1-\sigma}\left[p(1-x) F\left(c_{b}\right) r-p(1-x) F\left(c_{b}\right) \eta_{b}-p(1-x) c_{b}\right] \\
& +\frac{\sigma}{1-\sigma}\left[p(1-x) F\left(c_{b}\right) \alpha-p(1-x) F\left(c_{b}\right) \beta\right]
\end{aligned}
$$

And because of $y\left(c_{b}\right)_{\min }>y\left(c_{a}\right)_{\max }$, we could get the condition that $y\left(c_{b}\right)_{\min }=y\left(c_{a}\right)_{\max }$ is

$$
x_{2}=1-\frac{1-s-\eta_{a}}{A\left\{\left(1-s-\eta_{a}\right)^{2}-c_{b}\left[\alpha+r-\eta_{b}-\beta-1\right]\right\}}
$$

That means when $x>x_{2}$, enterprises just choose ECP. That illustrated that ECP exists easily in the enterprises which have long distance of knowledge, because it is more convenient for those enterprises to use ECP. And their knowledge have great heterogeneity, the heterogeneous knowledge are helpful to knowledge innovation [15-16]. When $x_{2} \geq 1$, enterprises wouldn't only choose ECP, so the condition that enterprises just only choose TP is $x_{2}<1$. Set

$$
c_{b 2}=\frac{\left(1-s-\eta_{a}\right)^{2}}{\alpha+r-\beta-\eta_{b}-1}
$$

That means only if when $c_{b}<c_{b 2}$, might exists the situation that enterprises only choose TP. Finally we could get the condition that enterprises should only choose TP is: $x>x_{2}$ and $c_{b}<c_{b 2}$. 


\subsection{The Critical Condition that Enterprises Choose Hybrid Pattern}

From the analysis above we can get the critical condition that enterprises only choose TP is: $x<x_{1}$, the critical condition that enterprises only choose ECP is: $x>x_{2}$. When $x_{1} \leq x \leq x_{2}$, we could get $y\left(c_{a}\right)_{\min } \leq y\left(c_{b}\right)_{\max }$ and $y\left(c_{b}\right)_{\min } \leq y\left(c_{a}\right)_{\max }$, then enterprises choose hybrid pattern, as long as we could prove that $x_{2} \geq x_{1}$. Because of

$$
x_{2}-x_{1}=\frac{1}{A}\left\{\frac{\left(1-\eta_{a}-s\right)+\sqrt{2 c_{b}\left[\alpha-\beta+r-\eta_{b}\right]}}{\left(1-\eta_{a}-s\right)^{2}-2 c_{b}\left[\alpha-\beta+r-\eta_{b}\right]}-\frac{1-\eta_{a}-s}{\left(1-s-\eta_{a}\right)^{2}-c_{b}\left[\alpha+r-\eta_{b}-\beta-1\right]}\right\}
$$

Comparing the numerator and the denominator of (7), it is easily to know $x_{2}-x_{1}>0$, which is $x_{2}>x_{1}$. We can get $c_{b 1}<c_{b 2}$ in the same way.

From above, we can get the enterprises' selection mechanism in Table 2.

Table 2. The Enterprises' Selection Mechanism

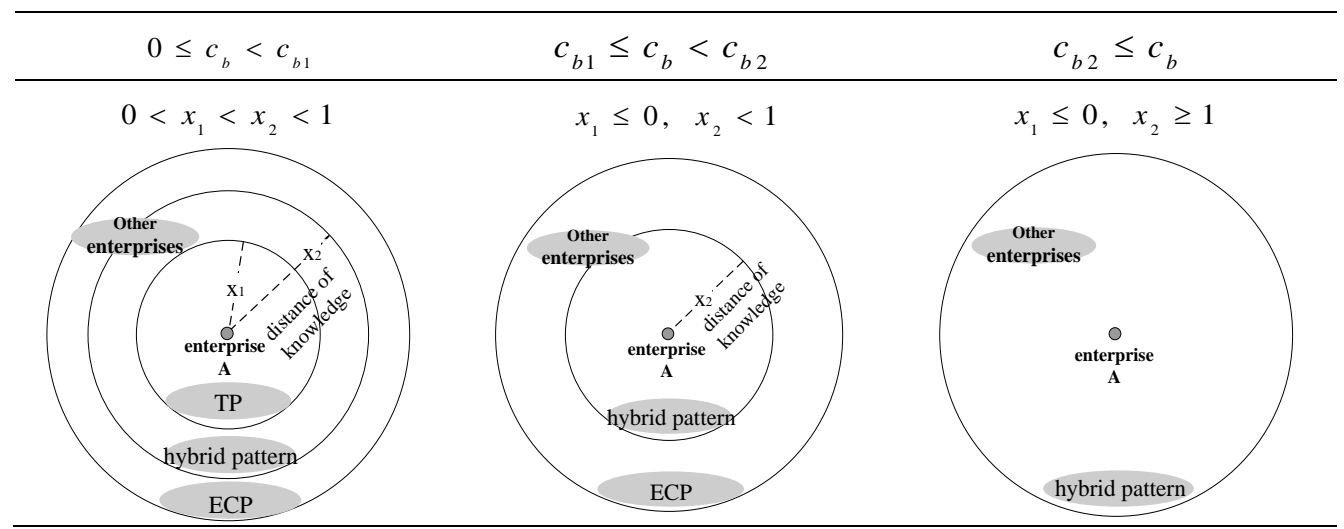

Before carrying on the knowledge trading, enterprises should analyze and calculate $x_{1}$ and $x_{2}$ according to the specific factors, such as trading risk and the explicitness of knowledge. Then combining the distance of knowledge to make decisions according to the result above and set the appropriate $c_{b}$. But in fact, the specific factors' change would change $x_{1}$ and $x_{2}$ and affect the final result on choosing trading patterns. So it is necessary to research these factors' influence on choosing trading patterns.

\subsection{Variable Analysis}

Through the analysis of influence factors, we can get the following result.

Table 3. Each Factor's Influence on the Selection Mechanism

\begin{tabular}{|c|c|c|c|c|c|c|c|c|}
\hline & $\alpha$ & $s$ & $r$ & $\beta$ & $\eta_{a}$ & $\eta_{b}$ & $c_{b}$ & $A$ \\
\hline$\frac{\partial x_{1}}{\partial(\cdot)}$ & - & - & - & + & - & + & - & + \\
\hline$\frac{\partial x_{2}}{\partial(\cdot)}$ & - & - & - & + & - & + & - & + \\
\hline
\end{tabular}




\section{Conclusion}

The paper induces the operation characteristics and influence factors of two patterns and construct mathematical model to analyze the trading mechanism. The result shows that when agency fee, risk cost of ECP and trading potential increase, the possibility that enterprises choose TP increase, too; with the increase of the explicitness of knowledge, searching cost, trading incentive, the risk cost of TP and reserve cost of ECP, the possibility that enterprises choose ECP gets increased; when the reserve cost of ECP become big enough, that would make enterprises be more willing to choose hybrid pattern.

The predecessors' researches about knowledge trading model just aimed to one single pattern (TP or ECP), they didn't research the selection mechanism. The paper analyze the selection of trading patterns under specific situation by constructing model, so we illustrate the selection mechanism better and solve the problem better, at the meanwhile we expand the research. The former research mentioned that searching cost would affect the knowledge trading of TP, and agency fee and trading risk affect the trading of ECP, there are mostly qualitative analysis and few model analyses. Our paper uses quantitative analysis to research the factors that could affect the selection of two trading patterns, illustrates the selection mechanism more detailed and imitate the operation process of two patterns more realistic.

Our research provides theoretical reference to the practice of enterprises management. The supplier should make sure the distance of knowledge and set the appropriate reserve cost, then weigh our the cost and profit and choose the trading pattern; the demander should make sure the searching cost, the agency fee of ECP and trading incentive in order to choose the trading pattern; the network service providers should construct more perfect trading mechanism and credit rating mechanism to decrease the trading risk and agency fee, that would be helpful to enlarge the number of enterprises who choose hybrid pattern.

\section{Acknowledgement}

This work was supported by Grants from The National Social Science Fund of China (no. 12CGL049), Grants from MOE (Ministry of Education in China) Project of Humanities and Social Sciences (no. 11YJC630110).

\section{References}

[1] H. W. Chesbrough, "Open innovation: The new imperative for creating and profiting from technology", Harvard Business Press, (2003).

[2] E. Almirall and R. Casadesus-Masanell, "Open versus closed innovation: A model of discovery and divergence”, Academy of management review, vol.35, no.1, (2010), pp. 27-47.

[3] E. Huizingh, "Open innovation: State of the art and future perspectives", Technovation, vol.31, no.1, (2011), pp. 2-9.

[4] M. P. Knudsen and T. B. Mortensen, "Some immediate-but negative-effects of openness on product development performance", Technovation, vol. 31, no.1, (2011), pp. 54-64.

[5] T. H. Davenport and L. Prusak, "Working knowledge: How organizations manage what they know", Harvard Business Press, (1998).

[6] D. G. Bell, R. Giordano and P. Putz, "Inter-firm sharing of process knowledge: Exploring knowledge markets", Knowledge and Process Management, vol. 9, no. 1, (2002), pp. 12-22.

[7] A. Afuah and C. L. Tucci, "Crowdsourcing as a solution to distant search", Academy of Management Review, vol. 37, no. 3, (2012), pp. 355-375.

[8] S. Ba, J. Stallaert and A. B. Whinston, "Optimal investment in knowledge within a firm using a market mechanism, Management Science, vol. 47, no. 9, (2001), pp. 1203-1219.

[9] E. Matson, P. Patiath and T. Shavers, "Stimulating knowledge sharing: Strengthening your organization's internal knowledge market”, Organizational Dynamics, vol. 32, no. 3, (2003), pp. 275-285. 
[10] X. Zhang, Y. Zhang and Q. Zhu, "Study on the Knowledge Market and the Model of Knowledge Trading among Enterprises in Supply Chain”, Journal of Industrial Engineering Management, vol. 22, no. 3, (2008), pp. 79-83.

[11] S. Yu, J. Ming and L. Xiong, "Study of the Internet Operating Mechanism Based on Witkey Mode", Information Science, vol. 31, no. 3, (2013), pp. 9-16.

[12] R. Ge and P. Zhang, "Comparative study of outsourcing mechanisms in online innovation market places", Journal of Management Sciences in China, vol. 13, no. 11, (2010), pp. 20-26.

[13] Y. Fang, W. Wang and C. Tan, "Reseach on Knowledge Services Optimization of Profit-oriented Witkey", Information Science, vol. 29, no. 10, (2011), pp. 1499-1504.

[14] M. Alavi and D. E. Leidner, "Review: Knowledge management and knowledge management systems: Conceptual foundations and research issues", MIS quarterly, vol. 25, no. 1, (2001), pp. 107-136.

[15] L. B. Jeppesen and K. R. Lakhani, "Marginality and problem-solving effectiveness in broadcast search", Organization Science, vol. 21, no. 5, (2010), pp. 1016-1033.

[16] K. R. Lakhani, L. B. Jeppesen, P. A. Lohse and J. A. Panetta, "The value of openness in scientific problem solving", Boston: Harvard Business School Working Paper, (2007).

[17] C. R. Taylor, "Digging for golden carrots: an analysis of research tournaments", The American Economic Review, vol. 85, no. 4, (1995), pp. 872-890.

[18] D. Liu, G. Ray and A. B. Whinston, "The interaction between knowledge codification and knowledge-sharing networks", Information Systems Research, vol. 21, no. 4, (2010), pp. 892-906.

[19] G. E. Bolton and A. Ockenfels, "ERC: A theory of Equity, Reciprocity, and Competition", The American Economic Review, vol. 90, no. 1, (2000), pp. 166- 193.

[20] Y. Yang, P. Chen and P. Pavlou, "Open Innovation: An Empirical Study of Online Contests", Proceedings of Thirteenth International Conference on Information Systems, Phoenix, (2009).

[21] H. Chesbrough, Open Business Models: How to Thrive in the New Innovation Landscape. Harvard Business School Press, Cambridge, MA, (2006).

[22] C. Terwiesch and Y. Xu, "Innovation contests, open innovation, and multiagent problem solving", Management Science, vol. 54, no. 9, (2008), pp. 1529-1543.

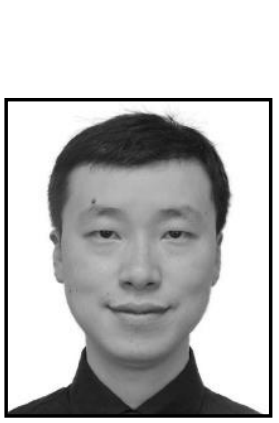

\section{Author}

Yi Li, he is an Associate Professor in the School of Economics and Management, Chongqing University of Posts and Telecommunications, China. He received his Ph.D. in Management from Chongqing University, China. His research interests are in the fields of technological innovation and knowledge management.

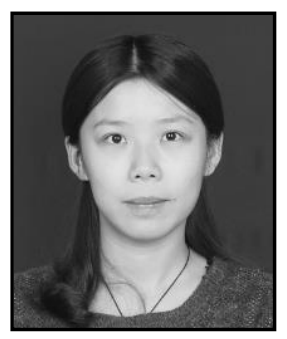

Yuanjie Ni, she is a Postgraduate in the School of Economics and Management, Chongqing University of Posts and Telecommunications, China. Her research interests are in the fields of technological innovation and knowledge management.

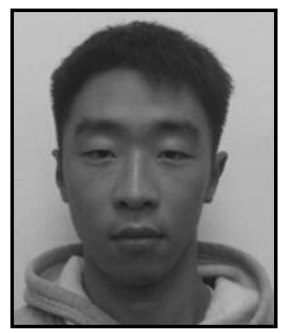

Wei Liu, he is a Postgraduate in the School of Economics and Management, Chongqing University of Posts and Telecommunications, China. His research interests are in the fields of technological innovation and knowledge management. 
Wenxing Yan, he is a Postgraduate in the School of Economics and Management, Chongqing University of Posts and Telecommunications, China. His research interests are in the fields of technological innovation and knowledge management. 
International Journal of $u$ - and e- Service, Science and Technology Vol.8, No.1 (2015) 